\title{
Comparative Evaluation of Analgesic, Antipyretic \& Anti-Inflammatory Effects of Various Extracts of Dried Fruit of Illicium verum Hook.f (Star anise) in Rodents
}

\author{
Hafiza TUSEEF ${ }^{1}$, Muhammad Liaquat RAZA ${ }^{2,3, *}$ and Tahira $\operatorname{ASSAD}^{4}$ \\ ${ }^{1}$ Department of Pharmacology, Bahria University Medical and Dental College, Karachi, Pakistan \\ ${ }^{2}$ Department of Pharmacology, Faculty of Pharmacy, Hamdard University, Karachi, Pakistan \\ ${ }^{3}$ Department of Pharmacy, Iqra University North Campus, Karachi, Pakistan \\ ${ }^{4}$ Department of Pharmacology, Karachi Institute of Medical Sciences, Malir Cantt, Karachi, Pakistan
}

('Corresponding author's e-mail: liaquathej@yahoo.com)

Received: 31 January 2020, Revised: 14 August 2020, Accepted: 1 September 2020

\begin{abstract}
The current investigation was designed to evaluate the analgesic, antipyretic, and anti-inflammatory effects of various extracts (methanol, ethanol, and aqueous) of dried fruit of Illicium verum hook.f, using 3 different doses $(150,250$, and $350 \mathrm{mg} / \mathrm{kg}$ p.o) to verify the traditional uses of this spice. In the hot plate model of analgesia, ethanol extract showed a significant reduction in pain in a dose-dependent manner compared to the control group. The maximum effect was observed at $350 \mathrm{mg} / \mathrm{kg}$ dosage i.e., $16.90 \pm 0.17 \mathrm{~s}$ compared to the control group i.e., $5.03 \pm 0.05 \mathrm{~s}$. The antipyretic activity was assessed in rats by Brewer's yeast induction. The methanol and ethanol extracts produced a significant reduction in rectal temperature compared to the control group throughout the three doses. The maximum effect was observed at 350 $\mathrm{mg} / \mathrm{kg}$ dosage of ethanol extract i.e., $37.1 \pm 0.8^{*}$ compared to the control i.e., $39.1 \pm 0.3$. In the paw edema model, methanol and ethanol extracts disclosed a significant reduction in paw edema at $350 \mathrm{mg} / \mathrm{kg}$ of dose. The maximum effect was observed at $350 \mathrm{mg} / \mathrm{kg}$ dosage of ethanol extract i.e., $0.25 \pm 0.23^{*}$ compared to the control i.e., $0.97 \pm 0.4$. In a behavioral study, locomotor activity (rearing) and exploratory activity (grooming) in mice was reduced significantly at higher doses (350 mg/kg p.o) involving the three extracts. However, scratching was increased non-significantly at all doses compared to the control group. This study concluded that various extracts of Illicium verum hook.f showed significant analgesic, antipyretic, and anti-inflammatory effects at different doses in a dose-dependent manner with varying potencies. The ethanol extract was found to be more potent among all, followed by methanol and aqueous extracts, whereas maximum effects were observed at $350 \mathrm{mg} / \mathrm{kg}$ of dose.
\end{abstract}

Keywords: Analgesic, Anti-inflammatory, Antipyretic, Behavioral, Illicium verum hook.f

\section{Introduction}

Herbs and spices are traditionally used in medicine from generation to generation; therapeutically, they occupy a unique position in every culture for the prevention and treatment of disease due to their strong pharmacological activities and less toxicity [1]. Approximately, $80 \%$ of the population in African and Asian countries relies on traditional medicines for their primary health care [2]. Nonetheless, many of them require scientific testing and validation [3]. Numerous herbs and spices are comprised of several active chemical constituents and secondary metabolites, which contribute a significant role in medicine [4].

Illicium verum hook.f is one of the spices, that belongs to the family of Illiaceae. It is an averagesized native perennial tree grown in the Northeast Vietnam and Southwest China, formerly located in the 
tropic and subtropic areas of Asia and utilized as a traditional medicine in the East Asia. In 2002, the Chinese Health organization confirmed and validated that star anise is one of the items that used as "both food and medicine" [5].

Traditionally, the tea of star anise fruit is prepared by adding $0.5-1 \mathrm{~g}$ of star anise in $150 \mathrm{~mL}$ of water, used for various indications, such as cold, cough, laxative, increase metabolism, and for stomach aches at $0.06-0.6 \mathrm{~mL} /$ day. Nevertheless, various encapsulated products, such as ointments and even lozenges, indicated for respiratory tract illness, contain star anise oil at the dose of $0.050-0.200 \mathrm{~mL}$ [6].

Therapeutics areas covered by Illicium verum include diuretic, antibacterial, stimulant, carminative, odontalgic, and stomachic. It has been used in congestion, cough, asthma, and bronchitis due to its strong anti-bacterial and anti-fungal properties [6-8]. It is also a chief constituent of anti-tussive remedies and is used to refresh breath and facilitate digestion [9]. Star anise oil has beneficial effects in the treatment of rheumatism and lower back pain. It possesses anti-oxidant properties due to the presence of linalool [10]. The oil has tranquilizing and sedative actions on the nervous system [6,11].

The literature review suggested hypothermic effect produced by methanol extract of Illicium verum at the dose of $3 \mathrm{~g} / \mathrm{kg}$ and analgesic effect at the dose of $500 \mathrm{mg} / \mathrm{kg}$ on oral administration [12]. Some other studies reported the analgesic effect of shikimic acid derived from star anise, analgesic, and antiinflammatory effect of aqueous extract of star anise at 0.78 and $3.90 \mathrm{~g} / \mathrm{kg}$ of doses $[13,14]$. Recently one of the authors has reported in-vitro anti-inflammatory activity of plant extract. It was effective in inhibiting heat-induced albumin denaturation at different concentrations. Maximum inhibition of $77.87 \pm 1.55$ was observed at $500 \mu \mathrm{g} / \mathrm{mL}[15]$.

Recently, it is reported that essential oil of Illicium verum showed against Acinetobacter baumannii, a major human pathogen causing hospital-acquired infections [16]. According to some in-vitro studies this plant also possesses following activities: antioxidant, antidiabetic [17] antihelminth [18], and antifungal [19].

Based on the conventional consumptions of this spice in traditional Chinese medicine and its reported activities in the literature, we, therefore, designed this study to compare and evaluate the analgesic, anti-inflammatory, and anti-pyretic effects of 3 different extracts, i.e., methanol, ethanol, and aqueous extracts of dried fruit of Illicium verum hook.f.

\section{Materials and methods}

\section{Plant material}

Dried fruits of star anise (Illicium verum hook.f) were purchased from the Imtiaz Super Market, Gulshan branch, Karachi, recognized and authenticated by Prof. Dr. Iqbal Azher, Dean, Faculty of Pharmacy and Pharmaceutical Sciences, University of Karachi, Pakistan. The voucher specimen number (IV-01-17) was issued and the sample was deposited in the Department of Pharmacognosy, University of Karachi, Pakistan.

\section{Preparation of plant extracts}

\section{Methanol/ethanol extract preparation}

The dried fruits of Star anise (Illicium verum hook.f) in the form of raw material were air-dried then crushed after washing. The extract was prepared by addition of $500 \mathrm{~mL}$ methanol in approximately $100 \mathrm{~g}$ of star anise dried sample (in the coarse powder form). It was soaked for $24 \mathrm{~h}$ at room temperature with occasional shaking. The saturated material was then purified with the help of filter paper and the filtrate was collected separately. Afterward, methanolic extract was evaporated under reduced pressure in a rotary evaporator at $40^{\circ} \mathrm{C}$, followed by freeze-drying at $-30{ }^{\circ} \mathrm{C}$ in a freeze dryer. The final extract in the dried form was kept at $-20^{\circ} \mathrm{C}$ until used. The same procedure is repeated for ethanol extract in which we used ethanol as a solvent. The percentage yield of methanol and ethanol extracts was 31.7 and $34.5 \%$, respectively. 


\section{Aqueous extract preparation}

$500 \mathrm{~g}$ of dried fruit of Illicium verum hook.f was washed, air-dried, and crushed. It was taken in the round bottom flask and $500 \mathrm{~mL}$ distilled water was added to cover the material fully. Later, it was boiled in the water bath for $1 \mathrm{~h}$ at $90-95{ }^{\circ} \mathrm{C}$. The supernatants were removed and repeated. The supernatant materials were purified with the help of filter paper (Whatman no.1). Afterward, lyophilization was performed to concentrate the filtrate and the residue was termed as an aqueous extract. The aqueous extract was stored in an amber glass bottle at $-20{ }^{\circ} \mathrm{C}$ until further use. The percentage yield of aqueous extract was found to be $24.4 \%$.

\section{Phytochemical studies}

Different extracts of dried fruit of Illicium verum (Star anise) were subjected to preliminary phytochemical screening by applying qualitative tests for confirming the presence of phytoconstituents $[21,22]$. The presence of phytoconstituents was confirmed by TLC and the results are presented in Table 1.

Table 1 Qualitative analysis of various extracts of dried fruit of Illicium verum hook.f.

\begin{tabular}{lccc}
\hline \multicolumn{1}{c}{ Phytochemical } & $\begin{array}{c}\text { Methanol Extract of } \\
\text { I.Verum } \text { (MEIV) }\end{array}$ & $\begin{array}{c}\text { Ethanol Extract of } \\
\text { I.Verum } \text { (EEIV) }\end{array}$ & $\begin{array}{c}\text { Aqueous Extract of } \\
\text { I.Verum (AEIV) }\end{array}$ \\
\hline Alkaloids & + & ++ & + \\
Flavonoids & + & ++ & + \\
Glycosides & + & + & - \\
Phytosterols & + & + & - \\
Phenolic compound & + & + & + \\
Steroids & + & ++ & - \\
Saponins & + & ++ & - \\
Terpenoids & + & + & + \\
Triterpenoids & + & ++ & + \\
Tannins & + & & + \\
\hline
\end{tabular}

Absence of phytochemicals (-), Presence of phytochemicals (+), Presence of phytochemicals at high concentration $(++)$.

\section{Qualitative tests}

Test for alkaloids (Wagner's test)

Two $\mathrm{mL}$ of each extract was dissolved in $1 \%$ dilute hydrochloric acid and filtered. Filtrate treated with Wagner's reagent (Iodine in potassium Iodide). Reddish-brown precipitate indicates the presence of alkaloids.

\section{Test for flavonoids}

One $\mathrm{mL}$ of each extract was taken added with $1 \mathrm{~mL}$ of $10 \%$ lead acetate solution. The formation of a yellow precipitate indicates the presence of flavonoids.

\section{Test for glycosides}

Each extract was hydrolyzed with $\mathrm{HCl}$ solution and neutralized with $\mathrm{NaOH}$ solution. A few drops of Fehling's solution A and B were added. The formation of a red precipitate indicates the presence of glycosides. 


\section{Phytosterols}

One $\mathrm{mL}$ of each extract was added into $2 \mathrm{~mL}$ of acetic anhydride and $2 \mathrm{~mL}$ of concentrated $\mathrm{H}_{2} \mathrm{SO}_{4}$. Change in color from violet to blue indicates the presence of sterol.

\section{Test for phenolic compounds}

One drop of $\mathrm{FeCl}_{3}$ was added into each extract and showed an intense violet color, indicating the presence of phenolic compounds.

\section{Test for steroids (Liebermann Burchard reaction)}

Two hundred $\mathrm{mg}$ of each extract was added with $10 \mathrm{~mL}$ of chloroform. Two $\mathrm{mL}$ of this filtrate reacted with $2 \mathrm{~mL}$ of acetic anhydrides and concentrated $\mathrm{H}_{2} \mathrm{SO}_{4}$. The formation of a blue-green ring indicates steroids' presence.

\section{Test for saponins}

One $\mathrm{mL}$ of each extract was diluted with $20 \mathrm{~mL}$ of distilled water in the test tube. It was shaken with a hand for $15 \mathrm{~min}$. The appearance of the foamy lather layer indicates the presence of saponins.

\section{Test for terpenoids (Salkowski test)}

Five $\mathrm{mL}$ of each extract was mixed with $2 \mathrm{~mL}$ of chloroform with the addition of $3 \mathrm{~mL}$ conc. $\mathrm{H}_{2} \mathrm{SO}_{4}$. The formation of reddish-brown color indicates the presence of terpenoids.

\section{Test for triterpenoids}

One $\mathrm{mL}$ of each extract was mixed with chloroform $(2 \mathrm{~mL})$ and then acetic anhydride $(1 \mathrm{~mL})$ and concentrated sulphuric acid $(1 \mathrm{~mL})$ was added to the solution. The formation of reddish-violet color indicates the presence of triterpenoids.

\section{Test for tannins}

About $0.5 \mathrm{~g}$ of each extract was boiled in $10 \mathrm{~mL}$ of water in the test tube and then filtered. The brownish-green color appeared after the addition of $0.1 \% \mathrm{FeCl}_{2}$ which indicates the presence of tannins.

\section{Chemicals and reagents}

All chemicals and drugs utilized were of analytical grade; Indomethacin (Indogesic, Wilson's pharmaceuticals, Pakistan), Aspirin (Disprin, Reckitt Benckiser Pakistan LTD), Acetaminophen (Paracetamol, GlaxoSmithKline), Carrageenan (Sigma Aldrich), and Brewer's yeast (GNC) was used as a standard.

\section{Animals selection}

The study was performed on healthy Wister albino rats of either sex, weighing between (150 - 250 $\mathrm{g}$ ), and albino mice $25-30 \mathrm{~g}$ of (6 - 8 weeks). Animals were purchased from the animal house of Dow University of Health Sciences, Karachi. Animals were housed in separate cages under standard conditions, humidity $(55-60 \%)$, and temperature $\left(23 \pm 2{ }^{\circ} \mathrm{C}\right)$. The circadian cycle of $12 \mathrm{~h}$ light and $12 \mathrm{~h}$ darkness was maintained. Animals were fed with the standard diet and water ad libtum. The apparent physical condition of these animals was monitored during this particular period. The inspection was done in the laboratory environment for a week before the administration of drugs. The entire experimental procedures, including the handling of animals, were operated by the National Institutes of Health guidelines and approved by the International Centre for Chemical and Biological Sciences (ICCBS) Animal Care and Use Committee.

Mice are preferably used for behavioral studies due to their similar anatomical, biochemical, and cellular features, similar brain functions such as memory, anxiety, aggression, and other emotional responses and genetic resemblance with humans. However, a rat is preferred over a mouse as a model of human disease and for cognition studies because of its large size and similar physiology. The proportional 
size of substructures facilitates the assessment of how much of the organ is involved in the experimental lesion and the distant effects of drug administration to the specific anatomical areas [22,23].

\section{Acute toxicity testing}

The acute toxicity was evaluated according to the OECD 423 guidelines [24]. Different doses of all extracts $(100,200,500,700,1,000,1,200,1,500,1,800,2,000 \mathrm{mg} / \mathrm{kg}$ p.o) were administered to the 3 groups of mice. However, the control group received only a vehicle. Groups were observed for $48 \mathrm{~h}$ period for any toxic signs and symptoms and mortality. Results of acute toxicity showed that this drug is safe up to the dose of $2,000 \mathrm{mg} / \mathrm{kg}$.

\section{Behavioral study}

The behavior of animals such as rearing, grooming, and scratching were examined after $20 \mathrm{~min}$ (oral administration) of Illicium verum extracts (methanol, ethanol, and aqueous) at 3 different doses $(150,250$, and $350 \mathrm{mg} / \mathrm{kg})$, each having $(n=6)$ animals. Table 2 depicts the results of behavior pattern changes, which were recorded by the comparison between the extracts and control group that received 0.5 $\mathrm{mL}$ normal saline correspondingly.

Table 2 Observation of bevioural activities (Rearing, Grooming, and Scratching) of methanol, ethanol, and aqueous extracts of Illicium verum hook.f.

\begin{tabular}{lllll}
\hline Treatment & Dose $(\mathbf{m g} / \mathbf{k g})$ & Rearing & Grooming & Scratching \\
\hline Control & $0.5 \mathrm{~mL}$ & $12.6 \pm 1.3$ & $19.2 \pm 2.0$ & $8.9 \pm 1.7$ \\
Methanol Extract & 150 & $6.9 \pm 2.3^{*}$ & $8.9 \pm 1.2^{*}$ & $9.3 \pm 1.5$ \\
(MEIV) & 250 & $4.6 \pm 1.4^{*}$ & $6.7 \pm 1.8^{*}$ & $9.5 \pm 2.4$ \\
& 350 & $3.8 \pm 2.5^{*}$ & $3.3 \pm 0.7^{*}$ & $10.3 \pm 1.8$ \\
Ethanol Extract & 150 & $8.4 \pm 2.7$ & $7.4 \pm 1.4^{*}$ & $9.4 \pm 3.3$ \\
(EEIV) & 250 & $7.2 \pm 3.1$ & $3.6 \pm 0.6^{*}$ & $10.1 \pm 2.1$ \\
& 350 & $3.6 \pm 2.3^{*}$ & $2.9 \pm 0.8^{*}$ & $10.7 \pm 1.7$ \\
Aqueous Extract & 150 & $9.1 \pm 1.2$ & $7.1 \pm 1.5^{*}$ & $8.9 \pm 2.3$ \\
(AEIV) & 250 & $6.6 \pm 2.2$ & $3.1 \pm 0.5^{*}$ & $9.4 \pm 2.2$ \\
& 350 & $3.7 \pm 3.2^{*}$ & $2.3 \pm 0.2^{*}$ & $9.9 \pm 3.6$ \\
Morphine & 5 & $3.5 \pm 1.3^{*}$ & $3.4 \pm 0.7^{*}$ & $11.3 \pm 0.9$ \\
\hline
\end{tabular}

$\mathrm{N}=6$

MEIV = Methanol extract of Illicium verum

EEIV $=$ Ethanol extract of Illicium verum

AEIV $=$ Aqueous extract of Illicium verum

All values represent mean \pm S.E.M

$* p<0.05$ as compared to controls. 


\section{Analgesic activity}

\section{Hot plate method}

Mice and rat paws are extremely sensitive to heat and temperatures. As a result, the reaction of animals is licking and withdrawal of paws with jumping [25]. A hot plate comprises of the electrically heated surface, generally made up of copper or heated glass surface. Fifty-five to fifty-six ${ }^{\circ} \mathrm{C}$ temperature is controlled on an electric hot plate. The animal was placed on the hot plate and the time was recorded by stopwatch until the occurrence of liking or jumping. Evaluation of analgesic activity was checked on Wister albino rats of either sex weighing between $150-250 \mathrm{~g}$. Animals were distributed in 5 groups and each comprised of 6 were marked individually. The solution of Aspirin $(300 \mathrm{mg} / \mathrm{kg} / 10 \mathrm{~mL})$ was prepared in normal saline water that was used as a standard drug.

Three extracts of (Illicium verum hook.f) dried fruit at different doses such as $(150,250 \& 350$ $\mathrm{mg} / \mathrm{kg} / 10 \mathrm{~mL}$ p.o), were given to 3 different groups of animals. Food was withdrawn $12 \mathrm{~h}$ prior to the administration of drugs and extracts untill the completion of the experiment. The animals were placed on a hot plate after $60 \mathrm{~min}$ and observation was noted after $0,0.5,1,2$, and $3 \mathrm{~h}$ time intervals. The results of this experiment are tabulated in Table 3.

Table 3 Analgesic effects of methanol, ethanol, and aqueous extract of Illicium verum hook by using hotplate thermal induce pain responses in rats.

\begin{tabular}{|c|c|c|c|c|c|c|}
\hline \multirow{2}{*}{ Treatment } & \multirow{2}{*}{$\begin{array}{c}\text { Dose } \\
\text { (mg/kg) }\end{array}$} & \multicolumn{5}{|c|}{ Hot plate Reaction Time (s) } \\
\hline & & $\mathbf{0 ~ h}$ & $0.5 \mathrm{~h}$ & $1 \mathrm{~h}$ & $2 \mathrm{~h}$ & $3 \mathrm{~h}$ \\
\hline Control & $0.5 \mathrm{~mL}$ & $5.41 \pm 0.03$ & $5.73 \pm 0.02$ & $5.12 \pm 0.02$ & $5.44 \pm 0.23$ & $5.03 \pm 0.05$ \\
\hline Methanol Extract (MEIV) & $\begin{array}{l}150 \\
250 \\
350\end{array}$ & $\begin{array}{l}4.36 \pm 0.18 \\
4.78 \pm 0.23 \\
4.79 \pm 0.78\end{array}$ & $\begin{array}{l}4.35 \pm 0.27 \\
5.34 \pm 0.34 \\
5.21 \pm 0.56\end{array}$ & $\begin{array}{l}5.46 \pm 0.30 \\
5.46 \pm 0.50 \\
5.53 \pm 0.16\end{array}$ & $\begin{array}{l}5.68 \pm 0.3 \\
5.49 \pm 1.3 \\
5.91 \pm 1.2\end{array}$ & $\begin{array}{l}6.81 \pm 0.41 \\
6.31 \pm 0.36 \\
6.45 \pm 0.38\end{array}$ \\
\hline Ethanol Extract (EEIV) & $\begin{array}{l}150 \\
250 \\
350\end{array}$ & $\begin{array}{l}4.29 \pm 0.03 \\
4.28 \pm 0.04 \\
4.29 \pm 0.12\end{array}$ & $\begin{array}{l}6.19 \pm 0.30 \\
6.51 \pm 0.17 \\
7.64 \pm 0.25\end{array}$ & $\begin{array}{l}7.98 \pm 0.37 \\
5.42 \pm 0.52 \\
8.24 \pm 0.35\end{array}$ & $\begin{array}{l}8.51 \pm 0.31 \\
8.93 \pm 0.12 \\
9.89 \pm 0.56\end{array}$ & $\begin{array}{l}11.46 \pm 0.30 * \\
12.81 \pm 0.12 * \\
16.90 \pm 0.17 *\end{array}$ \\
\hline Aqueous Extract (AEIV) & $\begin{array}{l}150 \\
250 \\
350\end{array}$ & $\begin{array}{l}4.98 \pm 1.21 \\
4.87 \pm 0.89 \\
4.67 \pm 0.78\end{array}$ & $\begin{array}{l}5.23 \pm 0.43 \\
5.51 \pm 0.45 \\
5.81 \pm 0.95\end{array}$ & $\begin{array}{l}5.81 \pm 0.34 \\
5.93 \pm 0.21 \\
6.32 \pm 0.45\end{array}$ & $\begin{array}{l}6.11 \pm 0.12 \\
6.42 \pm 0.34 \\
6.65 \pm 0.67\end{array}$ & $\begin{array}{l}7.22 \pm 1.21 \\
7.73 \pm 1.03 \\
7.94 \pm 0.98\end{array}$ \\
\hline Acetylsalicylic acid (ASA) & 300 & $4.7 \pm 1.2$ & $6.6 \pm 4.5$ & $9.90 \pm 0.7 *$ & $13.9 \pm 0.6^{*}$ & $19.34 \pm 1.3 *$ \\
\hline $\begin{array}{l}\mathrm{N}=6 \\
\mathrm{MEIV}=\text { Methanol extract } \mathrm{o} \\
\text { EEIV = Ethanol extract of } I \\
\text { AEIV = Aqueous extract of } \\
\text { All values are presented as } 1 \\
* P<0.05 \text { as compared to co }\end{array}$ & $\begin{array}{l}\text { Illicium ver } \\
\text { cium verun } \\
\text { licium vert } \\
\text { ean } \pm \text { S.E.M } \\
\text { trols. }\end{array}$ & & & & & \\
\hline
\end{tabular}

\section{Antipyretic activity}

The antipyretic activity was evaluated on Wister albino rats distributed into 5 groups, each contains 6 animals. A solution of $15 \%$ yeast $(10 \mathrm{~mL} / \mathrm{kg} /$ bodyweight $)$ was used to induce pyrexia in rats by subcutaneous injection [26]. The rectal temperature was recorded before and after $24 \mathrm{~h}$ injection of yeast solution. However, the test group was given $10 \mathrm{~mL}$ orally of different doses i.e. 150, 250, and 350 $\mathrm{mg} / \mathrm{kg} /$ body weight of methanol, ethanol, and aqueous extract respectively. Normal saline $(1 \mathrm{~mL}) \mathrm{was}$ given to the control group and the standard reference drug group was treated with $1 \mathrm{~mL}$ Paracetamol $(100 \mathrm{mg})$ in an aqueous solution. The post-treatment temperature of each animal was recorded before drug $18 \mathrm{~h}$ and after $0,1,2,3$, and $4 \mathrm{~h}$ drug treatment. The results of antipyretic effects are presented in Table 4. 
http://wjst.wu.ac.th

Table 4 Antipyretic effects of methanol, ethanol, and aqueous Extract of Illicium verum hook.f on brewer's yeast induced pyrexia in rats.

\begin{tabular}{llllllll}
\hline \multirow{2}{*}{ Treatment } & $\begin{array}{l}\text { Dose } \\
\mathbf{m g} / \mathbf{k g}\end{array}$ & \multicolumn{7}{c}{ Before Drug } & \multicolumn{4}{c}{ After Drug } \\
\cline { 2 - 7 } & & $\mathbf{- 1 8 ~ h}$ & $\mathbf{0 ~ h}$ & $\mathbf{1 ~ h}$ & $\mathbf{2 ~ h}$ & $\mathbf{3 ~ h}$ & $\mathbf{4} \mathbf{~ h}$ \\
\hline Control & $0.5 \mathrm{~mL}$ & $36.7 \pm 0.3$ & $37.4 \pm 1.3$ & $39.8 \pm 0.5$ & $39.4 \pm 0.6$ & $39.4 \pm 0.4$ & $39.1 \pm 0.3$ \\
& & 5 & & & & & \\
Methanol & 150 & $36.7 \pm 0.4$ & $38.1 \pm 0.4$ & $39.0 \pm 0.7$ & $38.5 \pm 0.1$ & $38.3 \pm 0.2$ & $37.2 \pm 0.12^{*}$ \\
Extract & 250 & $37.2 \pm 0.6$ & $38.0 \pm 0.1$ & $39.1 \pm 0.5$ & $38.6 \pm 0.3$ & $37.9 \pm 0.1$ & $37.5 \pm 0.41^{*}$ \\
(MEIV) & 350 & $37.8 \pm 0.3$ & $38.1 \pm 0.5$ & $39.0 \pm 0.2$ & $38.4 \pm 0.4$ & $37.6 \pm 0.2^{*}$ & $37.3 \pm 0.61^{*}$ \\
Ethanol & 150 & $38.2 \pm 0.1$ & $38.8 \pm 0.8$ & $38.3 \pm 0.6$ & $38.0 \pm 0.2$ & $37.8 \pm 0.3$ & $37.2 \pm 0.7^{*}$ \\
Extract & 250 & $37.4 \pm 0.5$ & $38.0 \pm 0.1$ & $38.0 \pm 0.3$ & $37.9 \pm 0.1$ & $37.4 \pm 0.1^{*}$ & $37.2 \pm 0.3^{*}$ \\
(EEIV) & 350 & $37.8 \pm 0.3$ & $38.7 \pm 0.5$ & $38.1 \pm 0.9$ & $37.8 \pm 0.3$ & $37.5 \pm 0.2$ & $37.1 \pm 0.8^{*}$ \\
Aqueous & 150 & $37.7 \pm 0.6$ & $38.9 \pm 0.4$ & $38.8 \pm 0.3$ & $38.5 \pm 0.9$ & $38.3 \pm 0.5$ & $37.9 \pm 0.1$ \\
Extract & 250 & $37.5 \pm 0.3$ & $38.7 \pm 0.7$ & $38.4 \pm 0.2$ & $38.4 \pm 0.3$ & $38.2 \pm 0.4$ & $37.8 \pm 0.3$ \\
(AEIV) & 350 & $37.6 \pm 0.1$ & $38.4 \pm 0.5$ & $38.7 \pm 0.2$ & $38.3 \pm 0.5$ & $38.1 \pm 0.6$ & $37.9 \pm 0.4$ \\
Paracetamol & 100 & $37.5 \pm 0.4$ & $38.9 \pm 0.06$ & $38.7 \pm 0.7$ & $37.5 \pm 0.01^{*}$ & $37.6 \pm 0.3^{*}$ & $37.3 \pm 0.2^{*}$ \\
\hline
\end{tabular}

$\mathrm{N}=6$

MEIV = Methanol extract of Illicium verum

EEIV $=$ Ethanol extract of Illicium verum

AEIV = Aqueous extract of Illicium verum

All values are presented as mean \pm S.E.M

$* P<0.05$ as compared to control.

\section{Anti-inflammatory activity}

\section{Model of carrageenan-induced paw edema}

Carrageenan-induced paw edema test was performed as described by Winter et al. [27]. Animals (rats) were divided into 5 groups and each group contained 6 animals. After 30 min, control group animals were orally treated with distilled water $(10 \mathrm{~mL} / \mathrm{kg})$. The standard group of animals was given indomethacin $(10 \mathrm{mg} / \mathrm{kg})$ and test drug methanol, ethanol, and aqueous extracts of Illicium verum hook.f $(150,250$, and $350 \mathrm{mg} / \mathrm{kg})$ were given to their respective groups. Edema was induced by injection of carrageenan $(1 \% \mathrm{w} / \mathrm{v})$ in normal saline $(0.1 \mathrm{~mL} / \mathrm{kg})$ into the right hind paw subplantar of each animal. The edema of paw thickness was measured after 1, 2, 3, 4, and $5 \mathrm{~h}$ by using a plethysmometer presented in Table 5. 
http://wjst.wu.ac.th

Table 5 Anti-inflammatory effects of methanol, ethanol, and aqueous extract of Illicium verum hook on carrageenan induced paw edema model in rats.

\begin{tabular}{llcccccc}
\hline & & \multicolumn{7}{c}{ Time (h) } \\
\cline { 3 - 7 } Treatment & Dose $(\mathbf{m g} / \mathbf{k g})$ & $\mathbf{0}$ & $\mathbf{1}$ & $\mathbf{2}$ & $\mathbf{3}$ & $\mathbf{4}$ & $\begin{array}{c}\text { Average edema } \\
\text { formation } \\
\text { (mm) }\end{array}$ \\
\hline Control & $0.5 \mathrm{~mL}$ & - & $0.51 \pm 0.06$ & $0.79 \pm .06$ & $0.89 \pm 0.7$ & $0.97 \pm 0.4$ & $0.78 \pm 0.47$ \\
Methanol Extract & 150 & - & $0.63 \pm 0.3$ & $0.83 \pm 0.45$ & $0.73 \pm 0.34$ & $0.53 \pm 0.91$ & $0.68 \pm 0.15$ \\
(MEIV) & 250 & - & $0.61 \pm 0.12$ & $0.57 \pm 0.36$ & $0.54 \pm 0.44$ & $0.51 \pm 0.34$ & $0.55 \pm 0.31$ \\
& 350 & - & $0.31 \pm 0.24$ & $0.29 \pm 0.20$ & $0.26 \pm 0.16$ & $0.26 \pm 0.26^{*}$ & $0.29 \pm 0.21^{*}$ \\
Ethanol Extract & 150 & - & $0.51 \pm 0.33$ & $0.49 \pm 0.31$ & $0.42 \pm 0.07$ & $0.39 \pm 0.21$ & $0.45 \pm 0.22$ \\
(EEIV) & 250 & - & $0.47 \pm 0.12$ & $0.41 \pm 0.34$ & $0.34 \pm 0.06$ & $0.28 \pm 0.33$ & $0.37 \pm 0.20^{*}$ \\
& 350 & - & $0.23 \pm 0.37$ & $0.27 \pm 0.4$ & $0.39 \pm 0.18$ & $0.25 \pm 0.23 *$ & $0.28 \pm 0.45^{*}$ \\
Aqueous Extract & 150 & - & $0.63 \pm 1.2$ & $0.66 \pm 0.8$ & $0.78 \pm 0.18$ & $0.73 \pm 0.23$ & $0.71 \pm 0.60$ \\
(AEIV) & 250 & - & $0.53 \pm 0.6$ & $0.67 \pm 1.2$ & $0.69 \pm 0.45$ & $0.56 \pm 0.33$ & $0.61 \pm 0.64$ \\
& 350 & - & $0.36 \pm 0.87$ & $0.45 \pm 1.7$ & $0.55 \pm 1.6$ & $0.59 \pm 0.48$ & $0.48 \pm 1.16$ \\
Indomethacin & 10 & - & $-0.39 \pm 0.7$ & $0.47 \pm 0.5$ & $0.43 \pm 0.3$ & $0.33 \pm 0.45^{*}$ & $0.25 \pm 0.48^{*}$ \\
\hline
\end{tabular}

$\mathrm{N}=6$

MEIV = Methanol extract of Illicium verum

EEIV = Ethanol extract of Illicium verum

AEIV = Aqueous extract of Illicium verum

All values are presented mean \pm S.E.M

$* P<0.05$ compared to control.

\section{Statistical analysis}

SPSS version 23 was utilized for statistics. Obtained results are presented as mean \pm S.E.M. Oneway ANOVA followed by post hoc Tukey's Honest Significant Difference (HSD) test was carried out for comparison with control. $P$-value $<0.05$ was considered as significant.

\section{Results and discussion}

Behavioral activities were altered by the administration of 3 different extracts (methanol, ethanol and aqueous) of Illicium verum at the doses of $(150,250 \& 350 \mathrm{mg} / \mathrm{kg})$. Table 2 shows that the locomotor activity (rearing) and exploratory activity (grooming) in mice was reduced significantly ( $p<$ $0.05)$ at higher doses $(350 \mathrm{mg} / \mathrm{kg} \mathrm{p.o})$ of all 3 extracts used. However, scratching was increased in animals at all doses as compared to the control group.

Analgesic activities of 3 extracts (methanol, ethanol, and aqueous) of Illicium verum, dried fruit were assessed at the doses of $(150,250$, and $350 \mathrm{mg} / \mathrm{kg}$ respectively) by the hot plate method. All the three doses of the ethanol extracts showed a significant reduction in pain response as shown in Table 3. Enhanced significant result $(p<0.05)$ was observed after $3 \mathrm{~h}$ at the dose of $350 \mathrm{mg} / \mathrm{kg}$ p.o of ethanol extract i.e., $16.90 \pm 0.17 \mathrm{~s}$ as compared to the control group i.e., $5.03 \pm 0.05 \mathrm{~s}$. However, the methanol and aqueous extracts showed non-significant results as compared to the control group. On the other hand, standard drug acetylsalicylic acid (Aspirin) at the dose of $300 \mathrm{mg} / \mathrm{kg}$ showed a more significant result i.e., $19.34 \pm 1.3 \mathrm{~s}$ as compared to the control group i.e., $5.03 \pm 0.05 \mathrm{~s}$. 
Values of antipyretic activity after $15 \%$ yeast solution administration in rats of all 3 extracts (methanol, ethanol, and aqueous) are tabulated in Table 4. The results revealed that methanol and ethanol extract at a dose of 250 and $350 \mathrm{mg} / \mathrm{kg}$ p.o produced more significant results $(p<0.05)$ to reduce the rectal temperature of rats after 3 and $4 \mathrm{~h}$, as compared to the control group. However, the aqueous extract of Illicium verum showed non-significant effects at all doses as compared to the control group. On the other hand, standard drug paracetamol at $100 \mathrm{mg} / \mathrm{kg}$ p.o produced more significant effects after 2, 3, and $4 \mathrm{~h}$ of pyrexia induction by $15 \%$ yeast solution in rats. The dose-dependent antipyretic effects of 3 extracts showed variation in their potency. The potency of antipyretic effects of all used 3 extracts were found as follows, EEIV > MEIV > AEIV. Results revealed that ethanol extract of Illicium verum is more potent and effective than methanol and aqueous extract of Illicium verum in reducing the rectal temperature in rats as shown in Table 4.

The results of the decrease of inflammation in paw edema of rats, which was induced by carrageenan $1 \% \mathrm{w} / \mathrm{v}$ solution are presented in Table 5. The inflammation of paw volume in rats was significantly reduced $(P<0.05)$ in methanol and ethanol test groups of Illicium verum as compared to the control group. The ethanol extract exhibited significant effects in edema reduction $(0.25 \pm 0.23 \mathrm{~mm})$ after 4 $\mathrm{h}$ as compared to the control group $0.97 \pm 0.4 \mathrm{~mm}$ at $350 \mathrm{mg} / \mathrm{kg}$ of dosage. The average value of edema formation of ethanol extract was $0.27 \pm 0.21 \mathrm{~mm}$; however, the control group showed a $0.78 \pm 0.47 \mathrm{~mm}$ value. However, the effective reduction of paw edema by 3 extracts followed this order EEIV $>$ MEIV $>$ AEIV.

\section{Discussion}

Previous researchers reported various pharmacological activities of Illicium verum hook.f (Star anise), encompassing carminative, stomachic, anti-rheumatic, chemopreventive, and anti-flu drug [28,29]. Phytochemical studies have revealed numerous valuable biomedical active constituents present in this spice, including anethole, anisaldehyde, trans-anethole, limonene, shikimic acid, sesquiterpenes, caryophyllene, $a$-pinene, squalene, eucalyptol, and several others from different part of star anise [30,31]. Anethole is the major constituent, more than $90 \%$ present in star anise responsible for several medicinal properties [32]. The current study investigated and identified the potency and effectiveness of the active constituents present in Illicium verum of three different extracts of previously reported analgesic, antipyretic, and anti-inflammatory activities. The three different extracts (methanol, ethanol and aqueous) of the Illicium verum showed dose-dependent variation in pharmacological activities.

The results of behavioral models of animal studies revealed that these three extracts (methanol, ethanol, and aqueous) decreased the grooming (exploratory) and rearing (locomotor) activities which might be due to the depression of the central nervous system. The excitatory monoamines neurotransmitter released from CNS is responsible for performing motor activities and exploratory behaviors [33]. Anethole is the main constituent of star anise, proven for psychoactive effects [34]. Therefore, the general depressant effects might be due to a decline in the release of neurotransmitters by these extracts as morphine also reduced the behavioral activities [35]. However, an increase in the body scratching activity in animals was observed when compared to the control group which received simple normal saline. It is also reported that active constituent anethole and trans-anethole present in star anise are responsible to produce strong anxiolytic and CNS effects [36].

Previous studies on some fraction of Illicium verum signified that this spice has anxiolytic-like effects and increase immobility in mice is due to the presence of trans-anethole. The results of the current investigations disclosed that ethanol and methanol extracts produced more significant effects on grooming and rearing. This supported and validated the prior findings of anxiolytic and sedative properties of this spice as reported earlier [35].

The evaluation of analgesic activity in the hot plate method by the three extracts (methanol, ethanol, and aqueous) showed that ethanol extract produced more significant results than methanol and aqueous extract of Illicium verum. Similarly, the potency of ethanol extracts was found more in reducing pyrexia in rats as compared to methanol and aqueous extract. Thus, the active constituents, e.g., alkaloids, flavonoids, and saponins in the ethanol, produce more pronounced effects. Squalene is one of the major 
constituents widely present in star anise, has been proved as an immune-modulating agent to strengthen the body and resist fatigue [37].

The yeast contains protein which is responsible to produce fever by an inflammatory reaction, in addition to other pro-inflammatory cytokines in the brain, which is responsible for increasing body temperature including interleukin (IL-1 $\beta$ and IL-6), interferon (IFN- $\alpha$ ), tumor necrosis factor (TNF- $\alpha$ ), prostaglandins (PGE2 and PGI2) [38]. For the management of pyrexia, standard drug paracetamol is used to reduce the level of prostaglandins by inhibiting cyclooxygenase enzymes, which release antiinflammatory signals from the brain at the site of injury. Illicium verum showed similar antipyretic action to reduce body temperature as seen with standard drug paracetamol. The previous studies validated that the presence of active constituents 3,4 Oxoisopropylidene-shikimic acids (ISA) in Illicium verum produced anti-inflammatory and peripheral analgesic effects by the inhibition of chemical mediators such as cytokines and prostaglandin E2 production [39-41]. All the extracts of the Illicium verum showed favorable results and reduced inflammation. Although, the anti-inflammatory action of ethanol extract was found more significant than methanol and aqueous extracts in reducing paw edema of rats.

Numerous investigations of medicinal plants revealed the presence of secondary metabolites such as flavonoids and alkaloids, which are found to possess analgesic, antipyretic, and other therapeutic properties. The research reported that eucalyptol present in star anise is responsible for reducing pain and inflammation by the destruction of leukemia cells in vitro [41]. Flavonoids are the major component to impede biosynthesis of the eicosanoids pathway as well as inhibiting the release of arachidonic acid by reducing neutrophils degranulation. As a result of these, end products inflammatory mediators such as prostaglandin and lipoxygenase suppresses which is the leading cause of inflammation, fever and pain [42]. Recently, one of the study reported that anti-inflammatory activity of Illicium verum is partly due to the reduction of some inflammatory mediators by supression of NF-kB pathway [43]. The preliminary screening of the Illicium verum confirmed the presence of the above-mentioned constituents. Therefore, it is assumed that antipyretic, anti-inflammatory, and analgesic activities of Illicium verum are due to the presence of phytochemical constituents within it.

\section{Conclusions}

This study concluded that various extracts of Illicium verum hook.f showed significant analgesic, antipyretic and anti-inflammatory effects at different doses in a dose-dependent manner with varying potencies. The ethanol extract was found to be more potent among all followed by methanol and aqueous extracts, whereas maximum effects were observed at $350 \mathrm{mg} / \mathrm{kg}$ of dose. Hence, maximum health benefits will be attained by regular consumption of probiotics of this spice. Further investigation is required to reveal the actual mechanism of their constituents.

\section{Acknowledgment}

We are thankful to Bahria University Medical and Dental College, Karachi for their unconditional support and encouragement. We wish to thanks to lab staff of Bahria University for their technical assistance.

\section{References}

[1] E Ernst. Harmless herbs? A review of the recent literature. Am. J. Med. 1998; 104, 170-8.

[2] LC Winslow and DJ Kroll. Herbs as medicines. Arch. Intern. Med. 1998; 158, 2192-9.

[3] PJ Houghton. The role of plants in traditional medicine and current therapy. J. Altern. Complement. Med. 1995; 1, 131-43.

[4] HR Vasanthi and RP Parameswari. Indian spices for healthy heart - an overview. Curr. Cardiol. Rev. 2010; 6, 274-9.

[5] GW Wang, WT Hu, BK Huang and LP Qin. Illicium verum: A review on its botany, traditional use, and pharmacology. J. Ethnopharmacol. 2011; 136, 10-20. 
[6] S Gafner. The hand book for practice on scientific basis. In: M Wichtl (Ed.). Herbal drugs and phytopharmaceuticals. $3^{\text {rd }}$ ed. CRC Press, Boca Raton, United States, 2004. p. 46.

[7] V Preedy. Essential oils in food preservation, flavor and safety. In: L Rocha and LAC Tietbohl (Eds.). Star anise (Illicium verum Hook) oils. Academic Press, 2016, p. 751-6.

[8] D Yazdani, S Rezazadeh, G Amin, MAZ Abidin, S Shahnazi and H Jamalifar. Antifungal activity of dried extracts of anise (Pimpinella anisum L.) and star anise (Illicium verum Hook, f.) dermatophyte and saprophyte fungi. J. Med. Plants 2009; 8, 24-9.

[9] P Kang, KY Kim, HS Lee, SS Min and GH Seol. Anti-inflammatory effects of anethole in lipopolysaccharide-induced acute lung injury in mice. Life Sci. 2013; 93, 955-61.

[10] MH Shahrajabian, W Sun and Q Cheng. Chinese star anise (Illicium verum) and pyrethrum (Chrysanthemum cinerariifolium) as natural alternatives for organic farming and health care: A review. Aust. J. Crop Sci. 2020; 14, 517-23.

[11] KS Rao, NK Keshar and BVVR Kumar. A comparative study of polyphenolic composition and Invitro antioxidant activity of Illicium verum extracted by microwave and soxhlet extraction techniques. Indian J. Pharm. Educ. Res. 2012; 46, 228-34.

[12] T Nakamura, E Okuyama and M Yamazaki. Neurotropic components from star anise: Illicium verum Hook. fil. Chem. Pharm. Bull. 1996; 44, 1908-14.

[13] J Deng, L Huang, Y Xie, Z Du, E Hao and X Hou. The anti-inflammatory and analgesic effects of star anise, an aromatic herb in south China. In: Proceedings of the $29^{\text {th }}$ International Horticultural Congress on Horticulture: Sustaining Lives, Livelihoods and Landscapes. Brisbane, Australia. 2014, p. 151-60.

[14] J Lin, QX Lan, YF Wei, LY Liao and GF Wei. An experimental study of the extraction procedure of medicinal components from star anise and its analgesic function (in Chinese). J. Youjiang Med. Coll. National. 2008; 30, 195-6.

[15] R Paul and RV Geetha. Evaluation of anti-inflammatory action of Illicium verum: An in vitro study. Drug Invent. Today 2018; 10, 2441-4.

[16] A Luís, S Sousa, J Wackerlig, D Dobusch, AP Duarte, L Pereira and F Domingues. Star anise (Illicium verum Hook. f.) essential oil: Antioxidant properties and antibacterial activity against Acinetobacter baumannii. Flavour Fragr. J. 2019; 34, 260-70.

[17] KN Kalaivanam, R Dinesha and NS Kumar. Antioxidant and anti-diabetic activities of polyphenolenriched star anise (Illicium verum) seeds extract. Int. J. Biotechnol. Biochem. 2018; 14, 77-84.

[18] T Davuluri, S Chennuru, M Pathipati, S Krovvidi and GS Rao. In vitro anthelmintic activity of three tropical plant extracts on Haemonchus contortus. Acta Parasitologica 2019; 21, 11-8.

[19] MS Alhajj, M Qasem, ARJE Nabi and S Al-Mufarrej. In-vitro antibacterial and antifungal effects of high levels of Chinese star anise. Braz. J. Poult. Sci. 2019; 21, 1-8.

[20] D Ramakrishna,V Suvarchala, G Chaitanya and T Shasthree. Preliminary phytochemical screening of a medicinally important cucurbit citrullus colocynthis (L.) schard. Res. J. Chem. Environ. 2019; 23, 41-55.

[21] I Toma, D Dahiru and M Madusolumou. Preliminary phytochemical analysis and in vitro antimicrobial study of the root and stem bark extracts of Ficus sycomorus Linn. Eur. J. Med. Plants 2019; 28, 1-10.

[22] PV Meer and J Raber. Mouse behavioural analysis in systems biology. Biochem. J. 2005; 389, 593610 .

[23] PM Lannaccone and HJ Jacob. Rats! Dis. Model. Mech. 2009; 2, 206-10.

[24] OECD Guideline for Testing of Chemicals. Guideline 423: Acute oral toxicity. Acute Toxic Class Method, 2001.

[25] I Igbe, BA Ayinde and A Izuchukwu. Anti-inflammatory and analgesic effects of the methanol stem bark extract of Brachystegia eurycoma Harms (Fabaceae). Eur. J. Med. Plants 2012; 2, 35665.

[26] BV Owoyele, S Oguntoye, K Dare, BA Ogunbiyi, EA Aruboula and A Soladoye. Analgesic, antiinflammatory and antipyretic activities from flavonoid fractions of Chromolaena odorata. J. Med. Plants Res. 2008; 2, 219-25. 
http://wjst.wu.ac.th

[27] CA Winter, EA Risley and GW Nuss. Carrageenan-induced edema in hind paw of the rat as an assay for antiinflammatory drugs. Proc. Soc. Exp. Biol. Med. 1962; 111, 544-7.

[28] MH Shahrajabian, W Sun and Q Cheng. Chinese star anise and anise, magic herbs in traditional Chinese medicine and modern pharmaceutical science. Asian J. Med. Biol. Res. 2019; 5, 162-79.

[29] N Mishra. Ethnopharmacological investigation of Indian spices. In: P Singh, N Mishra and E Gupta (Eds.). Phytochemistry and ethanopharmacology of Illicium verum (Staranise). IGI Global, Hershey, 2020, p. 93-105.

[30] JK Patra, G Das, S Bose, S Banerjee, CN Vishnuprasad, MDP Rodriguez-Torres and HS Shin. Star anise (Illicium verum): Chemical compounds, antiviral properties, and clinical relevance. Phytother. Res. 2020; 34, 1248-67.

[31] H Ohira, N Torii, TM Aida, M Watanabe, RL Smith. Rapid separation of shikimic acid from Chinese star anise (Illicium verum Hook. f.) with hot water extraction. Sep. Purif. Technol. 2009; 69, 102-8.

[32] AMV Ritter, TP Domiciano, WA Verri, AC Zarpelon, LGD Silva, CP Barbosa, MRM Natali, RKN Cuman and C Bersani-Amado. Anti hyper-nociceptive activity of anethole in experimental inflammatory pain. Inflammopharmacology 2013; 21, 187-97.

[34] T Sultana, MA Mannan and T Ahmed. Evaluation of central nervous system (CNS) depressant activity of methanolic extract of Commelina diffusa Burm. in mice. Clin. Phytosci. 2018; 4, 5.

[35] M Miyagawa, T Satou, C Yukimune, A Ishibashi, H Seimiya, H Yamada, T Hasegawa and K Koike. Anxiolytic-like effect of Illicium verum fruit oil, trans-anethole and related compounds in mice. Phyther. Res. 2014; 28, 1710-2.

[36] D Chouksey, N Upmanyu and RS Pawar. Central nervous system activity of Illicium verum fruit extracts. Asian Pac. J. Trop. Med. 2013; 6, 869-75.

[37] SK Kim and F Karadeniz. Biological importance and applications of squalene and squalane. $A d v$. Food Nutr. Res. 2012; 65, 223-33.

[38] YY Sung, YS Kim and HK Kim. Illicium verum extract inhibits TNF- $\alpha$ - and IFN- $\gamma$-induced expression of chemokines and cytokines in human keratinocytes. J. Ethnopharmacol. 2012; 144, 182-9.

[39] B Avula, YH Wang, T Smillie and I Khan. Determination of shikimic acid in fruits of Illicium species and various other plant samples by LC-UV and LC-ESI-MS. Chromatographia 2008; 69, 307-14.

[40] Y Goda, F Kiuchi, M Shibuya and U Sankawa. Inhibitors of prostaglandin biosynthesis From Dalbergia odorifera. Chem. Pharm. Bull. 1992; 40, $2452-7$.

[41] M Tordera, ML Ferrandiz and MJ Alcaraz. Influence of anti-inflammatory flavonoids on degranulation and arachidonic acid release in rat neutrophils. Z. Naturforsch. C. J. Biosci. 1994; 49, 235-40.

[42] JY Sun, CY You, K Dong, HS You and JF Xing. Anti-inflammatory, analgesic and antioxidant activities of 3,4-ox0-isopropylidene-shikmic acid. Pharm. Biol. 2016; 54, 2282-7.

[43] SY Keum, KH Jegal, SM Park and M Hwangbo. Anti-inflammatory Effects of Illicium verum hook. f. via Suppression of NFאB Pathway. Herb. Formula Sci. 2016; 24, 243-57. 